This is the accepted manuscript of an article published by Taylor \& Francis in Ethnic and Racial Studies on the $5^{\text {th }}$ of November 2019, available online: https://doi.org/10.1080/01419870.2018.1533645 


\title{
Pending between care and control: institutional contradictions and daily practices of healthcare for migrants in irregular situation in Italy
}

\begin{abstract}
The inclusiveness of the Italian framework on migrants' healthcare is indisputable "on the book". However, we might wonder how access takes shape at the front-line of the healthcare system in an increasingly hostile institutional and discursive environment. By focusing on Italian migration and healthcare policies and of health workers' practices in their encounters with migrants in irregular situation, this contribution analyses how institutional tensions are dealt with by - and simultaneously shape - workers' narratives and actions. It suggests that individual positioning plays a major role in favouring the adoption of discretional practices of care or control. Yet, daily practices are also mediated by the wider institutional and discursive landscape, which has been increasingly characterized by a tension between a medicalhumanitarian logic on the one hand, which legitimates the provision of healthcare to vulnerable migrants, and a control-oriented logic on the other, concerning immigration and health expenditure.
\end{abstract}

Keywords: Migration; Healthcare; Institutions; Street-level bureaucrats; Hostile environments; Italy.

\section{Introduction}

In the last decade, scholars have attempted to analyse the impact of the 2008 financial and economic crisis on migration policies (Papademetriou, Sumption, and Somerville 2009; Ponzo et al. 2015). Research has highlighted that, in context of crises, EU countries have introduced restrictions in migration inflows and migrants' access to social protection, targeting both EU and non-EU migrants to guard their welfare states against "abuses" (Lafleur and Stanek 2017).

Policies regulating access to healthcare for migrants are representative in this sense. In spite of international and (few) EU calls for providing appropriate access to healthcare services for migrants, and vulnerable migrants in particular, this policy field has been hardly improved in Europe (IOM 2016). Rather, since the 2008 economic crisis, restrictions on entitlement targeting vulnerable migrant groups have been reported in the Czech Republic, Spain and UK; limitations in coverage by raising means-test thresholds in Slovenia, Cyprus and Ireland; changes in the basis of entitlement from residence to insurance status in Latvia and, partially, Spain (Thomson et al. 2014).

From this perspective, healthcare systems are powerful institutional forces embodying ideas of in/exclusion, membership, belonging and identity. However, the concrete responsibility of drawing boundaries between those who deserve access to healthcare and those who do not is in the hands of street-level bureaucrats operating at the front-line of healthcare systems (Lipsky 1980; Marrow and Joseph 2015), whose context-specific interpretations of policy goals and social phenomena - like crises and migration in this case -matter.

Along with claiming for migrants' entitlement to healthcare (Ambrosini 2015), committed providers may modify and even bend restrictive health policies, adopting discretional practices to guarantee migrants' rights (Zincone 1998; Fernández-Kelly and Portes 2012). According to previous research (Devillé et al. 2011; Dauvrin et al. 2012, 6), thanks to "a deep rooting of humanism in the minds of pragmatic health professionals", health providers tend to adopt similar ethical-oriented practices, opening access to healthcare for excluded migrant groups.

Yet, health workers do not operate in isolated environments, but in contexts that are increasingly characterized by drastic cuts in public health spending, restrictive migration policies and pervasive anti-immigrant sentiments (Vanthuyne et al. 2013). Therefore, street-level workers' motivations and the institutional and discursive context in which they carry out their work should be simultaneously taken into account when investigating the migration-healthcare nexus in practice.

By drawing on an in-depth qualitative analysis of Italian policies and health workers' practices regulating access to public healthcare for migrants in irregular situation (undocumented migrants, pending asylum seekers, uninsured EU citizens in condition of economic indigence; hereafter: 
MIS), this contribution analyses how institutional contradictions in hostile environments are dealt with by - and simultaneously shape - health workers' practices at the front-line of healthcare systems.

To this end, the article outlines the Italian policy framework regulating access to healthcare for MIS in a context of restrictive immigration policies, raising anti-immigration sentiments, and ongoing rationalization of public healthcare expenditure. Then, after presenting the research strategy, it focuses on the narratives and practices carried out by health workers operating at the front-line of the Sistema Sanitario Nazionale (SSN) in Piedmont region, in the North of Italy. The findings suggest that institutional tensions are reproduced and even strengthened in workers' daily practices, reflecting a tension between a medical-humanitarian logic on the one hand, which legitimates the provision of healthcare to vulnerable migrants, and a control-oriented logic on the other, concerning immigration and health expenditure.

\section{The Italian framework: inclusive policies in a hostile context}

\section{Access to healthcare for MIS “on the book"}

Throughout the 1970s and 1980s, access to healthcare for MIS was a neglected formal right in Italy. Against this legislative vacuum, however, MIS could access public hospitals after finding health professionals and departments that were willing to provide health services to them on an informal basis (Zincone 1998). Thanks to the mediation of trade unions and voluntary associations, in cities like Turin, Piedmont capital city, health workers and local civil servants often adopted "benevolent contra legem practices" (ivi, 45) to guarantee access to healthcare for MIS.

In the early 1990s, the increasing Italian public debt, the economic crisis of September 1992 and the political bribe scandals of Tangentopoli, which exploded in the healthcare sector, completely transformed the institutional environment of the SSN, leading to its reform. Stricter controls and the principles of managerialism in the healthcare sector were introduced, obliging health workers to limit previous contra legem practices and to reduce informal services provided to MIS (ibid.).

However, due to increasing inflows of people after the outbreak of the civil wars in the Balkans (1991-1995) and thanks to a bottom-up mobilisation of health workers, non-governmental organizations and professional associations (Geraci and Bodini 2011), the issue of healthcare for MIS had momentum. After several emergency acts, in 1998 the first comprehensive Immigration Act was adopted. Paraphrasing the United Nation's Declaration of Human Rights, in its Preamble the Law affirms the duty of guaranteeing "fundamental human rights to foreigners, regardless of their legal status" (note: healthcare is the sole right explicitly defined as fundamental in the Italian Constitution). Then, it stipulates that MIS can access urgent, essential and continuous care ${ }^{2}$, pregnancy care and childbirth, child care, preventive care, prophylaxis and vaccinations, which must be provided free-of-charge in case of economic indigence by each Region's healthcare system. Access is opened through the issue of the "STP code" (Straniero Temporaneamente Presente temporary-present foreigner), which consists of an anonymous code that is given to MIS accessing healthcare for the first time. It is valid for six months but it can be renewed. As the Law states, registration can be carried out also if the person has no identity documents, and health workers cannot report MIS to the police when the latter require healthcare treatments.

Through a process of "boundary expansion" (Marrow and Joseph 2015) ${ }^{3}$, other vulnerable migrant categories have been included into this mechanism of public healthcare coverage over time. These include uninsured EU citizens who have been lived in Italy for more than three months but do not have enough resources to pay for a health insurance. For them, access to urgent, essential and continuous care is opened through a system of registration that replicates the STP one (for a detailed analysis on this issue, see: Perna 2018).

Likewise, in order to guarantee access to healthcare for asylum seekers from the time at which they arrive to Italy, the STP coverage has been extended to them until the issuance of a residence permit for asylum application, after which they are fully entitled to public healthcare. 
To summarise, over time different vulnerable migrant categories have been made equal in front of the Italian SSN. Access to public healthcare is provided through a reserved rather than universal trajectory, opened by the issue of the STP code. If a migrant in irregular situation get access to the system and during the six-month coverage period, she will be entitled to any urgent, essential or continuous care, as well as to pregnancy care and childbirth, child care, preventive care, prophylaxis and vaccinations.

Therefore, the inclusiveness of the Italian framework on this domain is indisputable "on the book", ranking first across EU countries according to the Health strand of the Migrant Integration Policy Index (http://www.mipex.eu/health). Nevertheless, since the early 2000s, several reforms in the policy fields of migration and healthcare, together with worsening public attitudes towards migration, have introduced contradictory goals and logics for action in the field.

\section{From the 2000s to date: turning towards a hostile environment}

Throughout the 2000s, Italy's immigration interventions have strengthened their focus on control, aimed at clamping down on irregular migration. Since the adoption of Law 189/2002 and Law $94 / 2009$ by right-wing governing coalitions including the anti-immigration party Northern League, immigration has been increasingly framed "as a question of security and public order" and "immigrants are presented as a population that is potentially dangerous and that needs to be under surveillance" (Triandafyllidou and Ambrosini 2011, 264; for an overview of migration policy reforms in Italy, see: Zincone 2011).

Although these measures did not directly modify articles addressing healthcare for MIS, they introduced several "pathogenic elements" affecting migrants' health (Geraci and Bodini 2011). For instance, by tying the permit of stay for working purposes to the duration of a job contract, these laws facilitate migrants' precariousness, which has harmful effects on health status. Likewise, by hindering the procedures concerning the regularization of MIS, they favour irregularity, which is a significant risk factor for migrants' health. In addition, a norm of the 2009 Law proposed by the Northern League intended to force public health workers to report to the police any migrants requiring healthcare who were not able to provide a valid residence document. This proposal triggered a vast mobilization of non-governmental organizations, professional associations and health professionals, named "Io non denuncio" (I do not report), leading to its withdrawal from the text of law. Nevertheless, it created an environment of fear and suspicion among MIS and health workers, affecting the accessibility of health services.

Hence, throughout the 2000s Italy's policies have coherently aimed at limiting "unwanted migration" and strengthening migrants' precariousness (Cappiali 2016). It is in such restrictive trend that the economic crisis broke out, reinforcing - rather than introducing - immigration controls. Increasing unemployment rates among regular migrant workers during the toughest years of the crisis allowed governments to make labour immigration almost impossible. As Decree Flows setting annual quotas for labour migration inflows show, the number of entries permitted for working purposes has been reduced by more than 80 per cent in the last ten years: from almost 170,000 entries permitted for non-seasonal employment in 2007 to 12,850 in $2018(-92.4 \%)$, and from 80,000 entries permitted for seasonal employment in 2007 to 18,000 in $2018(-77.5 \%)$. As a result, many migrants in Italy entered irregularly or with some kind of temporary visa, overstayed and went through a time of irregularity. Simultaneously, unemployed migrant workers already present in the country have increasingly been at risk of losing their regular status and become "undocumented". As many scholars point out (Triandafyllidou and Ambrosini 2011; Zincone 2011), the production of irregularity has been a systemic outcome of Italy's migration policy.

Then, at the turn of the decade, the exponential increase in asylum applications - from roughly 30,000 applications in 2008 to 130,000 in 2016 according to EUROSTAT data (2017) - led centreleft governments to strengthen even more controls against irregular migration, particularly through

the externalisation of border enforcement to neighbourhood countries and the multiplication of internal controls of mobility through centres for identification, reception, administrative detention and deportation (Oliveri 2017). 
In this restrictive policy environment, anti-immigration political discourses and public attitudes fuelled, depicting migrants as unwanted, undesirable, and undeserving of protection (Valtolina 2016). Nationals have increasingly questioned migrants' positive role in the Italian economy, and agree on reducing migrants' social rights and - alleged - privileges concerning welfare provisions, including access to healthcare (Ambrosini 2013). Asylum seekers have become the target of populist campaigns exaggerating the costs of reception and asking governments to support instead the Italian poor (Oliveri 2017,6). In this context, parties have progressively converged in their rhetorical arguments against immigration (Zincone 2011). Issues of security and the struggle against irregular migration have increasingly dominated the last political campaigns and contributed to the upsurge of anti-EU parties, including the Northern League and the 5 Stars Movement.

\section{Rationalization of healthcare and the issue of "medical tourism"}

Throughout the 1990s, reforms of the SSN have pursued efficiency and rationalization, with central government's interventions targeting overspending in healthcare, increasing fiscal controls over Regions and attributing to health workers the responsibility for controls (for a review, see Tediosi, Gabriele, and Longo 2009). However, it is since the outbreak of the 2008 crisis that central governments have introduced drastic austerity measures to reduce Italy's high public debt, significantly cutting expenditure in the provision of public health services (De Belvis et al. 2012). Among the recent measures adopted, a more rigid selection of healthcare beneficiaries has been presented as a central instrument to enhance the efficiency of the SSN and to reduce misuse and abuses of the system. Significantly, several of such measures have targeted the immigrant population, linking the rationalization of health expenditure with the need to stop a (supposed) "medical tourism", using migrants' legal and administrative status as element to exclude vulnerable and "inactive" foreign groups (Pasini and Merotta 2016). "In these times of crisis" - affirmed a MP of the Northern League - "we need to radically modify the Italian policy, which has allowed the entry of millions of not-chosen immigrants, whose protection affects the sustainability of our welfare and healthcare system." (Parliamentary question to the Ministry of Labour and Social Policies, October 13, 2011). For instance, since 2008 over-65 parents of non-EU migrants who entered the country for family reunification cannot be compulsorily registered with the SSN anymore, but they must pay voluntary insurance to get access to public healthcare. Similarly, since 2012 pregnant women coming from EU countries have the right to medical controls and childbirth only in case of unplanned childbirth (i.e. urgent or premature) during the first 90 days of presence in Italy. Otherwise, they will have to pay the full cost of medical controls and childbirth, against previous legislation that sanctioned the right for pregnant women to free-of-charge care regardless of legal status. Since 2013, asylum seekers must contribute to the health treatments they receive after two months from the asylum application, instead of previous six months and without any consideration of their contributive capacity, thus restricting EU criteria on this issue.

Overall, the "medical tourism" narrative has represented a powerful legitimating key to tighten controls in a context of scarce resources, charging health workers of stringently assess the eligibility of MIS to healthcare under the threat (albeit never concretely pursued) to make them pay for the costs of health services they provide - that should otherwise be denied - to non-enrollable MIS (information provided during the fieldwork on confidential basis). As Oliveri clearly points out (2017), critical social events, such as rising unemployment and reducing access to public services, have been increasingly framed and problematized in relation to race and migration. Racialization has thus functioned "as a powerful mechanism for displacing political responsibility and containing social anxieties" (3).

\section{Research strategy}




\section{Case selection}

This contribution presents the results of an ethnographic work carried out in the period 2014-2016 on migrant health policies in Piedmont and the "implementation gap". The focus on a representative Region depends on the regionalized structure of the SSN.

As presented before, the 1998 Immigration Act defines criteria concerning access to healthcare for migrants, and then leaves to each Region the responsibility to identify the most appropriate ways to guarantee access to healthcare for MIS. Although different initiatives have been undertaken on this field (Olivani and Panizzut 2016), the majority of Regions have created targeted public health structures. In particular, Piedmont Region provides healthcare to MIS though public Immigrants' Health Clinics (IHC) (a pseudonym), which employ trained administrative workers, health professionals and intercultural mediators who are in charge of, first, assessing MIS's eligibility to healthcare and, then, providing primary care to them.

Against Regions' legislative autonomy in this field, however, the central government exercises control in the wider healthcare domain by economic means, through the recourse to deficit reduction plans against Regions in case of noncompliance with the fiscal balance established at the national level. Since 2006 half of Italian Regions have been subject to deficit reduction plans (Ministry of the Economy 2015), including Piedmont. In particular, the Region has addressed rationalization in terms of "higher controls", "reduction in health prescriptions" and "responsibilization of health workers", who have been identified as cost-drivers in the system (Ministry of Health, Ministry of Economy and Finance, Piedmont Region, 29 July 2010).

Piedmont is a representative case among Italian regions also in terms of migration and asylum dynamics. It is characterized by a sizeable and growing foreign population: in 1992, foreigners represented $0.8 \%$ of the total regional population ( $1.0 \%$ on a national level), 9.6 per cent in 2016 ( $8.3 \%$ at the national level). Likewise, Piedmont faced a substantial increase in asylum applications during the last ten years: from 1,736 applications in 2007 to 14,000 in 2017 (from 13,310 to 130,119 applications on a national level in the same time-span).

\section{Data collection and analysis}

Data were collected through document analysis, focused interviews, and participant observation. Reviewed documents included national and regional documents on immigration and healthcare policies adopted in the period 1980-2016, and policy documents of non-governmental organizations, professional and voluntary associations concerned with MIS' health at the national and regional levels.

Face-to-face interviews were conducted with eight key decision-makers, twenty-three health professionals and thirteen administrative workers operating in three IHC. Interviews addressed participants' motivations for and experiences of providing care to MIS, the standard procedures they adopted in assessing MIS' eligibility to healthcare, and the practices that were taken on when dealing with complex cases due to migrants' health and/or legal status. Subject to prior authorization, interviews were audiotaped.

Participant observation was conducted at the clinics' registration desk and it mainly involved administrative workers and intercultural mediators. Nevertheless, it was common for health professionals to take part in the registration procedure, as they were the ones in charge of assessing the urgent and/or essential nature of the treatment needed by the person. Moreover, they could be found at the registration desk discussing specific cases during a break. Therefore, it became possible to also "observe" their narratives and practices.

Based on interview transcripts and field notes, data was coded and analysed with the support of Atlas.ti. A unique codebook was applied across the whole data set to compare participants' narratives and practices in relation to common themes. A priori concepts were mainly used in the definition of interpretative and theoretical codes, grounding on the street-level bureaucracy (Lipsky, 1980) and health-related deservingness literatures (Fernández-Kelly 2012; Willen 2012). However, in vivo codes were integrated in the process when specific keywords captured the essence of a 
piece. To further ensure data validity, findings and conclusions were discussed with academic scholars and research participants.

To conduct the research, a letter requesting authorisation was sent to clinic managers to explain the aim of the research, timing, techniques that would be used during the study and the ways personal data would be treated anonymously. Interviews and observation only started after receiving each organisation's approval. Likewise, health workers involved were informed about the research, its aim and methods. All names and data that could lead to the identification of participants were changed or removed.

This article contains some racially-charged interview excerpts that could hurt readers' sensitivity. They have been reproduced to illustrate the violence of encounters between some health workers and migrants, and of the processes of illegalization and racialization of MIS's behaviours that take shape on the street level.

\section{Health workers' practices at the front-line of the system}

As the previous discussion suggests, the Italian inclusive framework, which guarantees access to a large basket of healthcare services for MIS, is nowadays inserted into a wider hostile environment that has increasingly encouraged controls to limit both "unwanted migration" and "medical tourism". To deal with such tension, health workers involved in the research developed opposite strategies at the front-line of the system, adopting and adapting rules in daily encounters with MIS.

\section{Claiming against "clandestine" and "medical tourists"}

The most part of health workers involved in the research $(\mathrm{N}=21)$ believed that the Italian framework regulating access to the SSN for MIS is not strict enough. They stressed migrants' condition of irregularity as a rational choice, intentionally sought to "take advantage of the Italian universalistic system" (administrative worker).

Within this group, some of them $(\mathrm{N}=7 / 21)$ stressed MIS's illegality and disregard of the appropriate ways of conduct in the country according to Italian law and values. By defining them as "clandestine" or "illegal", "violent" or "unwilling to integrate", a cause-effect nexus was traced between the person's juridical status and her behaviour: as she voluntary entered and/or remained in the country without complying with immigration laws, she has no interest in respecting any law or shared value of the Italian society. As a doctor affirmed:

There are people going in and out of prisons so, what are you doing here in Italy? I mean, this is not fair! And so I grant less and less co-payment exemptions to them, in particular to Moroccans.

Likewise, another doctor argued that:

All Arabs have a problem. With women. A problem when it comes to respecting women. So, when they come here, they insult you, saying that "You do not understand a shit!" or "Do what I tell you to do!". They raise their voice because they think that this way they can obtain whatever they want.

As these pieces show, individuals were often equated with their countries, regions or even continents of origin (e.g. "Moroccans", "Arabs" and even "Africans"), reducing migrants and their individual biographies to ethnic or nationality markers. Moreover, these labels were often related to similar negative behaviours. Specifically, health workers considered that Albanians and Moroccans were the most problematic nationalities in daily encounters: they were portrayed as the most "violent", "hostile" and "disrespectful" users. ${ }^{4}$

From these workers' perspectives, once a minimum level of healthcare is provided to MISs, no additional efforts should be required, because "At the end, we are talking about clandestine people" (Francesco, doctor). Hence, these health workers assessed MIS's "cultural abidance over legal abidance" (Maynard-Moody and Musheno 2012, s17), defining and enforcing values of order, rights and good behaviour, and assessing MIS's deservingness of - and access to - healthcare on legality and moral criteria. 
The majority of these opposing health workers $(\mathrm{N}=14 / 21)$, however, defined MISs as malevolent "medical tourists" and "opportunist people". As an administrative worker stated:

I have to beg to get an appointment for me or for my girlfriend, and then wait for months. I have to pay $60 €$ for blood tests. And then, you see Romanians that arrive here and get free-of-charge healthcare... This is not right.

Therefore, MIS were portrayed as people who enjoy health services at the expense of those who should actually deserve it, that is, Italian citizens and taxpayers who are suffering from health service shortages. Romanians, in particular, were often depicted as people who instrumentally move to Italy to receive free-of-charge treatments that would be lacking or highly expensive in their country, thus taking advantage of their right to freely move across the EU. Even further, they were often represented as people who, although being - legally or illegally - employed in the Italian labour market, falsely argue to be in condition of economic indigence, because "they know that if they claim to be in such condition, they will not pay. And if you can avoid paying, then why should you [pay]?" (doctor). As these health workers interpreted MIS's access to healthcare as one of the main determinants contributing to SSN shortages, they believed that migrants arriving in Italy already affected by a severe pathology or pregnant migrant women should not be covered by the SSN, stopping their access to expensive health treatments.

Even more, they called for the re-introduction of limitations on the mobility of EU citizens, supported more controls of migration inflows and more effective deportation procedures, against a massive "invasion of economic immigrants" (read: they are not desperate people fleeing poverty and war, in the words of an intercultural mediator) and of "potential criminals and terrorists that may enter Italy disguised as refugees" (administrative worker).

From discourses to practices, this group of health workers carried out several exclusionary discretional practices on a daily basis, which may be included in two sets of strategies: i) reassessing true, which included multiplying questions about MIS' legal and economic conditions or insisting on inconsistencies about MIS' biographical stories to detect alleged lies (98 cases on 215 discretional practices of control coded during data analysis); and ii) re-defining criteria and coverage, which included asking for additional documents than the ones required by law at each encounter with MIS, or reducing the attribution of co-payment exemptions to them (117 cases on 215 practices of control). The following extract is a particularly clear example of how these strategies functioned and were legitimated by health workers.

After refusing to register a Turkish pregnant woman who had arrived to Italy only a few days before and was without documents, an administrative worker explained his decision to me. "Obviously, he was not her husband [the woman was accompanied by a man]! He had probably taken some money from her to become the fake foster parent of her children, or something similar. And, of course, she has her documents! But because she knew about the three-month issue, that everything before must be paid for, she said that she had lost her documents. Moreover, they said she is four-month pregnant. But, if he lives here, how exactly did she become pregnant? Was it the Holy Spirit? They are sly, aren't they? But if they try to hide the truth, I'll call their bluff! (smiling, satisfied). I know that directives actually state that, even without documents, the STP code should be issued. However, we have decided to ask for documents. You know, it is by hiding documents that they trick the system!"

Hence, health workers (re)created migrants' identities and histories to legitimize practices of exclusionary gatekeeping, distancing themselves from the realm of care while shifting to MIS the responsibility for exclusion. They acted as gatekeepers of the SSN, invoking an economic and moral rationale for exclusion. As a doctor clearly stated:

I think that if I know that you are not employed, I come to your home and I ask you: "How do you eat? Paying nothing? I mean, you either regularize yourself or you go away!". And maybe we, as doctors, should report them to the police. 
However, these health workers performed not only as "immigration gatekeepers", but also as "moral saviours", excluding those who - from their perspective - do not belong to the country's honest community that deserve access to healthcare.

\section{Claiming in favour of the "real deserving poor"}

The other group of health workers involved in the research $(\mathrm{N}=15)$ argued in favour of providing access to healthcare for MIS, depicting them as patients, i.e. sick people in need of care, whose condition of irregularity is caused by political and economic factors. They interpreted restrictions in immigration policies, migrants' precariousness and the absence of regularisations in the last years as the causes for migrants' irregularity. Likewise, they considered the mismanagement of the EUenlargement process as the determinant of EU citizens" "irregularity" in relation to the SSN.

The person's health status was the central concern in these health workers' discourses, in relation to which daily practices should be defined and performed. As an administrative worker argued, "We are not policemen. Of course we must be careful, but it is not our task to scan documents. We are responsible for people's health; we have to respond to their health needs".

Health workers' claims about having responsibility over MIS's health did not imply that they disrespected state's rules. Rather, some of them explicitly affirmed that being a healthcare giver is inherent to and required by the law itself, since 1998 Immigration Law defines MIS's right to access healthcare and the Italian Constitution defines healthcare as a fundamental right of each person. Moreover, health workers defending this position often stressed that guaranteeing healthcare to MIS is also in the best interest of the State, given that fewer resources are required in preventive and primary care compared to those needed to provide emergency care only. Despite their awareness about the critical financial condition of the SSN, they highlighted that use of medical resources by MIS was not a real issue, given that "the number of MIS compared to the general population accessing the public healthcare system is insignificant." (doctor).

However, moving from ideal discourses to practices, tensions often emerged. In ideal terms, these workers supported the right to access public healthcare for "real irregular migrants", "poor European citizens" and "real asylum seekers". At the same time, however, they expressed concerns and condemned abuses of scarce resources by "false indigent Europeans" and "rich migrants", calling for stricter controls. Therefore, they created hierarchies of MIS's deservingness of public healthcare on economic grounds, structuring their daily practices accordingly.

In particular, these health workers often adopted individual discretional practices of care when it implied intaking an affordable responsibility, that is, as long as they could offer primary care and treatments for free or at little cost. These included providing free samples of antibiotics or basic medicines, or allowing a person that could not be registered in the SSN to be examined by a doctor ( 52 cases on 95 discretional practices of care coded during data analysis). However, the higher the cost of treatments needed, the less such informal services could be put into practice. Consequently, strategies of scaling-up or directing-out entered the picture.

Specifically, when faced with a patient in need of expensive treatments, these health workers collectively engaged in order to scale the problem up to clinics' managers, trying to open alternative trajectories to healthcare for that person under the legitimacy (and economic responsibility) of the organization, as the following piece indicates.

The closing time was approaching when two Brazilian women entered the registration room, asking for the STP code. Hamid [intercultural mediator operating also as administrative worker] invited the two women to have a sit and asked them for their documents.

Hamid: We have a problem. You are from Brazil. The Italian government has stipulated an agreement with Brazil, so you have to bring with you a healthcare form from there. Do you have it?

Woman 1: No, I don't.

Woman 2: Neither do I.

Hamid: Ok... (grumbling). Why are you here [at the IHC]? 
The two women gave Hamid two envelops from the hospital. He opened them and read accurately the papers inside.

Hamid: Let me make a call. I'll get back to you in a couple of minutes.

Hamid went to the medical room. He came back a few minutes later, accompanied by the doctor and medical assistant in charge of the IHC that day. Then, he grabbed the phone. A man answered.

Hamid: Sergio, I have a problem. There are two women from Brazil here. (the medical line manager talking). Yes, I know that they should bring the form, but they do not have it. They have lived here for a year now. But, and this is the point, they both contracted HIV. What can I do? (a few seconds later, Sergio replied). Ok then, I'll call Mr. Leonardo [the high-level manager]. Hamid hang up the phone and immediately made another call. When the high-level manager replied, he explained the situation to him. A couple of seconds after, I heard Mr. Leonardo talking. Hamid agreed with what the high-level manager was saying. Then, he hanged up the phone and he turned towards the health professionals in the room.

Hamid: He said me to enrol them using a code valid for a month. This way, they can start the treatment [for the HIV] while the Foreign Office assesses their coverage situation in Brazil.

Doctor: Ok then. While you register them, I'll start examining them.

Hamid: Perfect! (he went out and called the two women). Give me your documents again, please, and follow the doctor.

However, successful strategies of scaling up were the exception (6 cases on 95 practices of care). Instead, directing out was the most frequent second-best strategy adopted by committed health workers when dealing with complex and expensive cases (37 cases on 95 practices of care), directing the patient to non-profit organizations or known professionals who could provide healthcare to the person out of the public system.

\section{Relating the macro and the micro. Practices, policies and contexts}

In his research about policies of exclusion at urban level in Italy, Ambrosini $(2013,152)$ argues that discourses and policies of exclusion "are in a position to influence, directly or indirectly, discourses, attitudes and daily practices [...]. They then have cultural effects that go far beyond their operational effectiveness."

This racialized boundary-making process emerges in the words and practices of health workers in their daily encounters with MIS, although with different features depending on workers' views and commitments. Although all health workers faced the same institutional contradictions in providing healthcare for MIS, the ways they interpreted social phenomena and reacted to tensions matter. Specifically, health workers endorsed one or another goal (care vs. control), taking on different stances towards policies in relation to their views about migrants" "illegality" and their own responsibilities and roles.

As Figure 1 summarizes, these boundary-making processes appear strongly coherent in their specific developments. When MIS were framed as patients, their health status represented the central concern of health workers, who considered themselves and behaved as healthcare givers, in charge of caring for MIS. When a tension between rules and the health status of the person emerged, health workers adopted discretional actions of care to include MIS into the healthcare system. However, the strategy through which inclusion was pursued depended on the cost of the specific service to be provided. At the opposite, when migrants accessing healthcare were framed as foreigners, health workers acted as gatekeepers and invoked the moral and economic side of control to exclude undeserving migrants from public healthcare.

\section{[FIGURE 1 here]}

Yet, the analysis also indicates that, while individual views and commitments played a major role in favouring the adoption of discretional practices "from below", these antithetical patterns of practices reproduce at the front-line the high divisiveness of the institutional context, suggesting the embedded nature of conceptions of "deservingness". Against an inclusive framework on MIS' right 
to healthcare, the progressive criminalisation and stigmatisation of "unwanted migrants" in immigration policies and public discourses, together with the reforms in the SSN invoking rationalization, the responsibilization of health workers and a more rigid selection of beneficiaries, introduced a tension in the field between a human rights-humanitarian logic on the one hand, which sustains the provision of healthcare services to MIS according to 1998 Law and the Constitution, and a control-oriented logic on the other, which legitimates restrictions in access.

Thus, against either individually-driven explanations or institutionally-bounded interpretations, the study suggests that, while health workers hold a certain degree of agency to the extent they may adopt discretional practices deviating from the law, the scope and content of discretion is mediated by the institutional and discursive environment in which health workers operate, which frames and constrains individuals' perception and use of discretion.

\section{Conclusions}

Until quite recently, scholars of the immigration-healthcare nexus have mostly paid attention to laws, regulations and policy documents to analyse the degree of migrants' access to healthcare within and across countries. This contribution highlights that the content of formal policies may be shaped and counterbalanced by the wider institutional and discursive landscape, resulting in ambiguous or even contradictory logics for everyday courses of action. Although in Italy healthcare is defined as a fundamental right of the person that must be ensured as such, since the early 2000 s and increasingly in recent times of crises, national policies and discourses have shifted towards an approach of control strengthening, in relation to both immigration and public healthcare expenditure. As a result, the inclusive policy frameworks regulating the access to healthcare for MIS nowadays is inserted into a larger hostile environment that in a more or less open way encourages exclusionary gatekeeping at the front-line of the healthcare system.

Although the focus on a single case may limit the statistical generalization of the research findings, this study appears fairly representative of the current events that are crossing Europe and beyond. Calls to stop migration flows and increasing protectionist stances against abuses of nationstates' social protection systems have increasingly presented restrictions in migrants' rights as inevitable. Previous studies on the US system highlight health workers' double burden of being responsible towards their patients' health status, while facing increasing pressures for system efficiency in times of rationalization of healthcare systems (Horton 2006; López-Sanders 2017). In France, Larchanché (2012) delineates a relation between discourses on budgetary restrictions, health providers' perceptions of economic insecurity and progressive restrictions in access to healthcare for MIS - to which they are legally entitled. Similarly, in Canada, Vanthuyne and colleagues (2013) argue that discourses on migrants' health-related deservingness highly depend on health workers' ideas about the affordability of medical treatments in a context of drastic cuts in economic resources. According to Webber (2014), a similar trend occurs in the UK, where the government introduced legislation that makes health workers responsible of acting as extensions of the UK's border police.

Next to confirming this pattern, this paper suggests that the rationalization of healthcare and the criminalization of migration is leading not just to the cross-deputization of front-line health workers as "immigration gatekeepers", but also as "moral or national saviours", excluding the "illegals" and "fraudsters" from the country's institutions as not belonging to the moral and economic members of the country's community. Further research at the point of entry of healthcare systems would be necessary to better understand the ways in which increasingly hostile discursive and institutional environments shape street-level work and, ultimately, affect migrants' rights.

\section{Endnotes}

1. Estimates concerning the presence of migrants in an irregular situation are not available at the regional level. Therefore, data refers to the foreign resident population. 
2. Coverage includes health services that are urgent (cannot be deferred without endangering the patient's life), or essential (preventative and curative). Care must be provided on continuous basis, that is, must proceed until the treatment and rehabilitation cycle is completed.

3. In analysing ethnic boundary-making in health policies after the 2010 Affordable Care Act in the US, Marrow and Joseph (2015) defines "boundary expansion" as the process through which new people have been included in a group from which they were previously excluded (the one of healthcare insured persons), such as racial minority and poor Americans.

4. Interestingly, these racially marked groups are the ones that have been affected the most by discourses of race and criminalization in Italy since the mid-1990s (Angel-Ajani 2003; Kosic and Phalet 2006).

\section{References}

Ambrosini, M.

2013. "We are against a multi-ethnic society': policies of exclusion at the urban level in Italy." Ethnic and Racial Studies 36(1): 136-155. DOI:10.1080/01419870.2011.644312.

2015. "NGOs and Health Services for Irregular Immigrants in Italy: When the Protection of Human Rights Challenges the Laws." Journal of Immigrant \& Refugee Studies 13(2): 116-134. DOI:10.1080/15562948.2015.1017631.

Angel-Ajani, A. 2003. "The Racial Economies of Criminalization, Immigration, And Policing in Italy." Social Justice 30(3): 48-62. www.jstor.org/stable/29768208.

Barretta, P., and G. Milazzo. 2016. Notizie oltre i muri. Quarto rapporto Carta di Roma 2016. Pavia: Associazione Carta di Roma e Osservatorio di Pavia. Accessed September 5, 2017. https://www.cartadiroma.org/wp-content/uploads/2016/12/Rapporto-2016_cartadiroma.pdf.

Cappiali, T.M. 2016. "Activism of immigrants in vulnerable conditions and radical-left allies: a case study of Italy's Struggle of the Crane." Journal of Ethnic and Migration Studies 42(15): 2508-2527. DOI: 10.1080/1369183X.2016.1169917.

Dauvrin, M., V. Lorant, S. Sandhu, W. Devillé, H. Dia, S. Dias, A. Gaddini, E. Ioannidis, N.K. Jensen, U. Kluge, R. Mertaniemi, R. Puigpinós i Riera, A. Sárváry, C. Straßmayr, M. Stankunas, J.J.F. Soares, and M. Welbel. 2012. "Healthcare for irregular migrants: pragmatism across Europe. A qualitative study." BMC Research Notes 2012 5: 99. DOI:10.1186/1756-0500-5-99.

de Belvis, A.G., F. Ferrè, M.L. Specchia, L.Valerio, G. Fattore, and W. Ricciardi. 2012. "The financial crisis in Italy: Implications for the healthcare sector." Health Policy 106(1): 10-16. DOI:10.1016/j.healthpol.2012.04.003.

Devillé, W., T. Greacen, M. Bogic, M. Dauvrin, S. Dias, A. Gaddini, N. Koitzsch Jensen, C. Karamanidou, U. Kluge, R. Mertaniemi, R. Puigpinós i Riera, A. Sárváry, J.J.F. Soares, M. Stankunas, C. Straßmayr, M. Welbel, and S. Priebe. 2011. "Healthcare for immigrants in Europe: Is there still consensus among country experts about principles of good practice? A Delphi study." BMC Public Health 2011 11: 699. DOI:10.1186/1471-2458-11-699.

EUROSTAT 2017. Asylum and first time asylum applicants by citizenship, age and sex. Annual aggregated data (rounded). Last update: July 21, 2017. Accessed August 1, 2017. http://appsso.eurostat.ec.europa.eu/nui/show.do?dataset=migr asyappctza\&lang=en.

Fernández-Kelly, P. 2012. "Rethinking the deserving body: altruism, markets, and political action in healthcare provision." Ethnic and Racial Studies 35(1): 56-71. DOI:10.1080/01419870.2011.594166.

Fernández-Kelly, P., and A. Portes. 2012. "Health care and immigration - understanding the connections." Ethnic and Racial Studies 35(1): 1-2. DOI:10.1080/01419870.2011.594177.

Geraci, S., and C. Bodini. 2011. "Network of networks for immigrants' health." Salute e Società X(2): 148161. DOI:10.3280/SES2011-002ENG010.

Horton, S. 2006. "The double burden on safety net providers: Placing health disparities in the context of the privatization of health care in the US." Social Science \& Medicine 63: 2702-2714. DOI: 10.1016/j.socscimed.2006.07.003.

IOM (International Organization for Migration). 2016. Recommendations on access to health services for migrants in an irregular situation: an expert consensus. October 2016. Accessed August 7, 2017. http://equi-health.eea.iom.int/index.php/9-uncategorised/336-expert-consensus. 
Kosic, A., and K. Phalet. 2006. "Ethnic categorization of immigrants: The role of prejudice, perceived acculturation strategies and group size." International Journal of Intercultural Relations 30: 769782. DOI:doi.org/10.1016/j.ijintrel.2006.06.003.

Lafleur, J-M., and M. Stanek. 2017. South-North Migration of EU Citizens in Times of Crisis. Cham: Springer Open. IMISCOE Research Series. DOI:978-3-319-39763-4_12.

Larchanché, S. 2012. "Intangible obstacles: Health implications of stigmatization, structural violence, and fear among undocumented immigrants in France." Social Science \& Medicine 74: 858-863. DOI:10.1016/j.socscimed.2011.08.016.

Law 6 March 1998, no. 40. Disciplina dell'immigrazione e norme sulla condizione dello straniero.

Law 30 July 2002, no. 189. Modifica alla normativa in materia di immigrazione e di asilo.

Law 15 July 2009, no. 94. Disposizioni in materia di sicurezza pubblica.

Lipsky, M. 1980. Street-level bureaucracy. Dilemmas of the individual in public services. New York: Russel Sage Foudation.

López-Sanders, L. 2017. "Changing the navigator's course: How the increasing rationalization of healthcare influences access for undocumented immigrants under the Affordable Care Act." Social Science \& Medicine 178: 46-54. DOI:10.1016/j.socscimed.2017.01.066.

Maynard-Moody, S., and M. Musheno. 2012. "Social Equities and Inequities in Practice: Street-Level Workers as Agents and Pragmatists", Public Administration Review 72(S1): S16-S23. DOI:10.1111/j.1540-6210.2012.02633.x.

Marrow, H.B. and T. D. Joseph. 2015. "Excluded and Frozen Out: Unauthorised Immigrants' (Non)Access to Care after US Health Care Reform." Journal of Ethnic and Migration Studies 41(14): 2253-2273. DOI: $10.1080 / 1369183 X .2015 .1051465$.

Ministry of the Economy. 2015. "Il monitoraggio della spesa sanitaria. Rapporto n.2." MEF Studi e $\begin{array}{lllll}\text { Pubblicazioni. } & \text { Roma. } & \text { Accessed } & \text { February } & \text { 8, }\end{array}$ http://www.rgs.mef.gov.it/ Documenti/VERSIONE-I/Attivit--i/Spesa-soci/Attivit-monitoraggioRGS/2015/IMDSS-RS02 1509 2015.pdf.

Ministry of Health, Ministry of Economy and Finance, Piedmont Region, 29 July 2010. Accordo tra il Ministero della Salute, il Ministero dell'Economia e delle Finanze e la Regione Piemonte per l'approvazione del Piano di rientro di riqualificazione e riorganizzazione e di individuazione degli interventi per il perseguimento dell'equilibrio economico ai sensi dell'articolo 1, comma 180, della legge 30 dicembre 2004, n. 311.

Olivani, P., and D. Panizzut. 2016. Attuale legislazione sanitaria italiana per gli immigrati irregolari e attuale fruibilità di tale legislazione a livello regionale. Milano: NAGA.

Oliveri, F. 2017. "Racialization and counter-racialization in times of crisis: taking migrant struggles in Italy as a critical standpoint on race." Ethnic and Racial Studies, DOI:10.1080/01419870.2018.1391404.

Papademetriou, D.G., M. Sumption, and W. Somerville. 2009. Migration and the Economic Downturn: What to Expect in the European Union. MPI Reports, Washington, DC: Migration Policy Institute. Accessed September 4, 2018. https://www.migrationpolicy.org/research/migration-and-economicdownturn-what-expect-european-union.

Pasini, N., and V. Merotta. 2016. "The Health of Migrants". In The Twenty-first Italian Report on Migrations 2015, edited by V. Cesareo, 41-47. Milano: McGraw-Hill Education.

Perna, R. 2018. "Re-bounding EU citizenship from below: practices of healthcare for '(Il)legitimate EU Migrants' in Italy." Journal of Ethnic and Migration Studies 44(5): 829-848, DOI:10.1080/1369183X.2017.1362977.

Ponzo, I., C. Finotelli, J. Malheiros, M.L. Fonseca, and E. Salis. 2015. "Is the Economic Crisis in Southern Europe Turning Into a Migrant Integration Crisis?" Politiche Sociali 1/2015: 59-88. DOI: $10.7389 / 79535$.

Sainsbury, D. 2006. "Immigrants' social rights in comparative perspective: welfare regimes, forms of immigration and immigration policy regimes." Journal of European Social Policy 16(3): 229-244. DOI:10.1177/0958928706065594.

Tediosi, F., S. Gabriele, F. Longo. 2009. "Governing decentralization in health care under tough budget constraint: What can we learn from the Italian experience?" Health Policy 90/2009: 303-312. DOI:10.1016/j.healthpol.2008.10.012.

Thomson, S., J. Figueras, T. Evetovits, M. Jowett, P. Mladovsky, A. Maresso, J. Cylus, M. Karanikilos, H. Kluge. 2014. Economic crisis, health systems and health in Europe: impact and implications for policy. Copenhagen: WHO Regional Office for Europe. 
Triandafyllidou, A., and M. Ambrosini. 2011. "Irregular Immigration Control in Italy and Greece: Strong Fencing and Weak Gate-Keeping serving the Labor Market." European Journal of Migration and Law 13(3): 251-273. DOI:10.1163/157181611X587847.

Valtolina, G.G. 2016. "Italian Society and Migration." In The Twenty-first Italian Report on Migrations 2015, edited by V. Cesareo, 57-64. Milano: McGraw-Hill Education.

Vanthuyne, K., F. Meloni, M. Ruiz-Casares, C. Ruosseau, A. Ricard-Guay. 2013. "Health workers' perceptions of access to care for children and pregnant women with precarious immigration status: Health as a right or a privilege?." Social Science \& Medicine 93: 78-85. DOI:10.1016/j.socscimed.2013.06.008.

Webber, F. 2014. "Extending immigration policing and exclusion in the UK." Race \& Class 55(3): 86-92. DOI:10.1177/0306396813509199.

Willen, S.S. 2012. "Migration, 'illegality', and health: Mapping embodied vulnerability and debating healthrelated deservingness." Social Science \& Medicine 74: 805-811. DOI:10.1016/j.socscimed.2011.10.041.

Zincone, G.

1998. "Illegality, Enlightenment and Ambiguity: A Hot Italian Recipe." South European Society and Politics 3 (3): 45-82. DOI:10.1080/13608740308539547.

2011. "The case of Italy." In Migration Policymaking in Europe. The Dynamics of Actors and Contexts in Past and Present, edited by G. Zincone, R. Penninx, and M. Borkert, 247-290. Amsterdam: Amsterdam University Press.

\section{Figures}

Figure 1. Patterns of discretional practices. 